\title{
MELHORIAS NO FLUXO INTERNO DE INFORMAÇÕES A PARTIR DA APLICAÇÃO DA FERRAMENTA QFD
}

\section{IMPROVEMENTS IN THE INTERNAL FLOW OF INFORMATION FROM THE APPLICATION OF QFD TOOL}

\author{
Leonardo Moraes Aguiar Lima dos Santos ${ }^{1}$; Daniel Augusto Hoppe ${ }^{2}$; André Luiz Emmel Silva ${ }^{3}$; \\ Patrícia Paz Silva ${ }^{4}$; Lucas Vinícius Reis ${ }^{5}$ \\ ${ }^{1}$ Universidade de Santa Cruz do Sul-UNISC-Santa Cruz do Sul/RS-Brasil \\ leomals@hotmail.com \\ ${ }^{2}$ Universidade de Santa Cruz do Sul-UNISC-Santa Cruz do Sul/RS-Brasil \\ danielhoppe@unisc.br \\ ${ }^{3}$ Universidade de Santa Cruz do Sul-UNISC-Santa Cruz do Sul/RS-Brasil \\ andresilva@unisc.br \\ ${ }^{4}$ Universidade de Santa Cruz do Sul-UNISC-Santa Cruz do Sul/RS-Brasil \\ patriciapaz2306@gmail.com \\ ${ }^{5}$ Universidade de Santa Cruz do Sul-UNISC-Santa Cruz do Sul/RS-Brasil \\ lucasviniciusreis@gmail.com
}

\begin{abstract}
Resumo
O fluxo de informações, a ética e a transparência organizacional são aspectos importantes para o sucesso das empresas. Este trabalho apresenta um estudo sobre as relações de cliente interno e fornecedor interno do setor de pré-impressão de uma indústria produtora de cigarros, com o uso de ferramentas da qualidade para analisar as relações. $O$ objetivo é analisar as relações internas de trabalho das áreas produtivas do setor e sugerir melhorias no processo interno de trabalho. $O$ estudo foi elaborado procurando ir ao encontro das necessidades identificadas em cada área. A metodologia adotada baseia-se em pesquisas bibliográficas e pesquisa-ação, focadas no mapeamento do processo interno e na descoberta dos pontos de maior importância nas relações. Através dos estudos realizados, foram identificadas as exigências dos clientes e os pontos principais para garantir a qualidade, no qual se evidencia uma grande necessidade de melhorar a comunicação interna entre as áreas. Os resultados apontam para a realização de uma ação para aumentar o nível de conhecimento dos projetos e do grau de conhecimento das áreas em relação ao funcionamento do setor e do trabalho sendo executados pelos colegas de outras áreas.
\end{abstract}

Palavras-chave: Desdobramento da função qualidade; Fluxo de Informação; Cliente Interno e Fornecedor Interno.

\section{Introdução}

Um dos fatores mais importante no processo produtivo de uma indústria é a relação entre os setores e áreas. O fluxo de informações, o fluxo de produção, a ética e a transparência organizacional são essenciais para o sucesso das empresas (ZOCCHE, 2011). Uma empresa ou setor, constituídos de diversas áreas formam uma rede interna de fornecedores e clientes, os quais 
são essenciais para o desempenho da empresa. O reconhecimento e o grau de sucesso dos relacionamentos internos, como forma de integração dos vários setores para atingir seus objetivos, são inegavelmente influenciados pela qualidade do atendimento e dos serviços prestados internamente, o que sugere a necessidade de as empresas monitorarem a qualidade do serviço em relação aos clientes e fornecedores internos (BORGES et al., 2008).

Em um processo de desenvolvimento, para que haja qualidade, devem existir procedimentos, métodos eficazes, equipamentos, ferramentas eficientes, pessoas habilitadas e treinadas, objetivando a eficiência do processo e eficácia do produto (CHERMONT, 2001). As ferramentas da qualidade são conceituadas como uma forma de melhorar e garantir a aceitação dos clientes externos em relação ao produto da empresa. Estas mesmas ferramentas podem ser traduzidas para uma interpretação e visão interna, considerando a relação cliente e fornecedor entre as áreas que se comunicam e trocam produtos e serviços dentro do processo produtivo. O objetivo é melhorar o processo de planejamento da qualidade e ganhar com a melhor identificação dos clientes internos (STEFANO et al., 2008; JURAN, 1994).

O QFD (Desdobramento da Função Qualidade) é uma ferramenta que implementa estratégias pata satisfazer as necessidades dos clientes (CHOWDHURY; QUADDUS, 2016), incorporando suas demandas ao longo do processo (KUBOTA; MIGUEL, 2013). As necessidades dos clientes podem ser desdobradas em qualidade do projeto e fornecimento, para o produto ou serviço, através do uso de matrizes. Essas matrizes contêm as informações e dados necessários para que a qualidade seja obtida, atuando como uma forma de comunicar sistematicamente a informação relacionada com a qualidade e de explicitar ordenadamente o respectivo trabalho (função) (MIGUEL, 2003).

Ferramentas da qualidade contemplam dois aspectos fundamentais, conhecido como desdobramento da qualidade e desdobramento da função. O desdobramento da qualidade é tradução das qualidades exigidas pelos clientes em características da qualidade do produto, processo e produção, representados por um conjunto de matrizes. O desdobramento da função, por sua vez, significa o desdobramento do trabalho, ou seja, a sequência, o registro e documentação de todas as funções operacionais e trabalho necessário para obtenção da qualidade desdobrada nas matrizes elaboradas (MIGUEL, 2003).

A gestão da qualidade no processo faz mérito a aspectos como o envolvimento de todas as atividades no processo, que devem contribuir de forma efetiva para aumentar a adequação do produto ao uso. Assim como, todos os clientes devem ser considerados, no caso dos clientes internos, considera-se que os setores seguintes ao processo são seus clientes, o trabalho a ser feito deve levar em conta as prioridades definidas por eles. Desta forma, será definida uma organização no processo produtivo (PALADINI, 1995). 
Um dos problemas encontrados no ambiente de estudo é o entendimento do fluxo de trabalho, de informações e do relacionamento interno entre as áreas do setor. Existe uma grande relação com clientes externos que influencia as relações internas, porém os colaboradores desconhecem a relevância das suas ações e de sua influencia sobre o trabalho das demais áreas. Sendo assim, o presente estudo tem por objetivo atender as necessidades dos clientes internos e melhoria da relação de trabalho entre as áreas do um setor de uma indústria produtora de cigarros, através da aplicação de ferramentas da qualidade. Sendo assim, o presente estudo tem por objetivo a aplicação da ferramenta QFD (Desdobramento da Função Qualidade) para a melhoria da comunicação e relação de trabalho, entre as áreas internas de uma gráfica de grande porte, localizada na região central do estado do Rio Grande do Sul. A gráfica em estudo possui 61 colaboradores, divididos internamente em sete áreas, responsáveis por fornecer arte e design de embalagens para uma empresa multinacional atuante na área de bens de consumo.

\section{Metodologia}

A pesquisa é de natureza aplicada, de caráter quali-quantitativo, implementada através de uma pesquisa-ação. Classifica-se como exploratória do ponto de vista dos objetivos, e bibliográfica em relação aos seus procedimentos técnicos. Os procedimentos metodológicos foram estruturados em 5 etapas: (i) Estudo teórico-conceitual; (ii) Definição do público alvo; (iii) Definição do instrumento de coleta de dados; (iv) Coleta de dados; (v) Análise dos dados.

O estudo teórico-conceitual ocorreu través de buscas em publicações da área (periódicos, livros e artigos), visando avaliar e compreender as contribuições científicas sobre a temática. O processo de questionário e coleta de dados teve como base o conceito de qualimetria, método que trata da aferição do grau de satisfação do cliente através de consulta direta, utilizando-se de questionários estruturados e questões abertas (MIRANDA, 1995). Sendo assim, primeiramente aplicou-se um questionário aberto (Q.Ab.), com até três pessoas chaves de cada uma das áreas, escolhidas de maneira aleatória. O questionário consiste em perguntas genéricas e globalizadas para entendimento e mapeamento das necessidades da gráfica, criadas a partir da visão dos autores em relação ao ambiente estudado. O mesmo está baseado em questões que buscam entender o grau de satisfação do entrevistado, em relação ao seu trabalho, a sua visão sobre o ambiente, suas percepções como cliente interno e como fornecedor interno, e ainda contempla questões que buscam por parte do entrevistado sugerir soluções as suas ideias de melhoria. Posteriormente as respostas foram estruturadas em questões diretas, sempre de acordo com o relato dos entrevistados iniciais, formando assim o questionário estruturado (Q.Es.), aplicado à todos os colaboradores.

As respostas obtidas pelas áreas foram avaliadas e posicionadas como voz do cliente nas questões pertinentes. As respostas da gerência e supervisão foram avaliadas e posicionadas 
conforme enquadramento na descrição de características exigidas e características da qualidade. Após as avaliações e definições das características exigidas, bem como das características da qualidade, avaliou-se as questões de mapeamento da área entre cliente interno e fornecedor interno, visando encontrar um fluxo de informação e um fluxograma das relações. Os demais itens do Q.Es. serviram como base para aplicação do método QFD, no qual através do desdobramento das matrizes identificou-se as prioridades e os processo mais adequados para melhorar o fluxo de trabalho entre as áreas.

\section{Fundamentação teórica}

\subsection{Gestão da Qualidade}

Para definir qualidade, é preciso atentar para o atendimento integral ao cliente. Para atender o cliente, é necessário ter qualidade no processo produtivo. Por isso, se é verdade que a qualidade começa e termina no cliente, também é verdade que a qualidade é projetada, desenvolvida e gerada no processo (PALADINI, 2006). As organizações precisam gerar produtos e serviços em condições de satisfazer as demandas dos usuários finais, sob todos os aspectos. Essa é uma exigência gerada muito mais pelas condições de competição no mercado do que pela capacidade do consumidor de impor, ao conjunto da indústria, suas pretensões (MIRANDA, 1995). Qualidade é um termo utilizado cotidianamente, mas, se diversas pessoas forem questionadas sobre o significado desse termo, dificilmente chegar-se-á a um consenso (CARVALHO; PALADINI, 2006).

O objetivo da qualidade nas organizações é disponibilizar produtos e serviços a seus clientes, de modo que excedam às necessidades e expectativas dos mesmos, gerando diferencial mercadológico em relação aos concorrentes. A importância da qualidade dos serviços e como as empresas devem atuar para alcançar a excelência nos serviços ressalta a importância de as empresas focarem as operações internas, o que faz emergir o conceito de serviços e clientes internos (CHERMONT, 2001; BORGES et al., 2008).

\subsection{Ferramentas da Qualidade}

Após entender que é necessário ingressar em um sistema de Gestão da Qualidade, as empresas se veem diante de um desafio que está longe de ser simples. O desafio consiste em descobrir de que forma deve ser feita a gestão, e como será possível melhorá-la. Diante disto, várias técnicas, ferramentas, sistemas e procedimentos vêm sendo colocados à disposição das empresas para fazer isto (MIRANDA, 1995). As ferramentas da qualidade são métodos e instrumentos utilizados para a melhoria de processos, desenvolvimento, medição, análise, melhoria da qualidade das organizações e solução de problemas. O uso das ferramentas permite operacionalizar 
efetivamente os princípios da gestão da qualidade contidos nos sistemas de gestão da qualidade ISO 9001. O objetivo é a clareza no trabalho e principalmente a tomada de decisão com base em fatos e dados, ao invés de opiniões (OLIVEIRA, 2011; MAICZUK; JÚNIOR, 2013).

\subsection{Desdobramento da Função Qualidade (QFD)}

Desdobramento da Função Qualidade (QFD) é empregado na direção do desenvolvimento e fornecimento de serviços sem falhas com base nos requisitos do cliente (KAMVYSI et al., 2014). Trata-se de uma ferramenta dinâmica, que envolve a empresa como um todo (PEROTTI; SCHMIDT; GODOY, 2009), e por meio de matrizes traduz as necessidades do cliente em termos de características que o produto ou serviço deve conter, a fim de encontrar a resposta ou solução às necessidades identificadas. O QFD gera, para cada um dos requisitos da qualidade (necessidade do consumidor), uma característica ou requisito técnico específico que deve conter o produto ou serviço, o mesmo deverá fazer parte do planejamento do processo e da produção (MIRANDA, 1995; FNQ, 2008). O princípio fundamental deste conceito é uma transformação sistemática dos requisitos e expectativas dos clientes em parâmetros de produtos e processos mensuráveis (HEERMANN et al., 2006). Objetiva enfocar os itens mais importantes, tanto do ponto de vista dos clientes quanto da empresa, proporcionando um mecanismo para alcançar vantagens competitivas (MIGUEL, 2008).

Ao utilizar a ferramenta, os requisitos e necessidades dos clientes (qualidades exigidas) são convertidos em características da qualidade. Dessa forma, surgem os atributos e especificações do produto, buscando o desdobramento da qualidade do projeto para o produto acabado através do uso de matrizes. Essas matrizes contêm as informações e dados necessários para que a qualidade seja obtida (MIGUEL, 2008). O desdobramento permite a combinação e transição da linguagem do cliente para a linguagem técnica, possibilitando a tomada de decisão em equipe. $\mathrm{O}$ desdobramento acontece dos requisitos (o que) para as características técnicas (como) através de avaliações das relações entre os requisitos e as características. As relações são avaliadas através de simbologias e pontuações - valores (SANTANA, 2004).

A ferramenta QFD está principalmente relacionada a etapa do ciclo de vida do desenvolvimento de produtos e planejamento do produtos dentro de uma empresa. No passado, as aplicações eram basicamente sobre produtos tangíveis, porém tem-se observado o crescente uso sobre produtos menos tangíveis, como serviços e softwares (CHENG; FILHO, 2010).

\subsection{Clientes internos e externos}

A maior parte dos produtos e processos das organizações existem para servir os clientes internos, ou seja, aqueles que fazem parte da mesma empresa e também são impactados pelas 
atividades dos demais. As relações internas tendem a ser informais, resultando em uma percepção obscura a respeito de quem são os clientes e como estes são afetados. Para identificar os clientes internos, normalmente é feito o acompanhamento do produto, utilizando fluxogramas (JURAN, 1994).

O cliente externo é aquele que não faz parte da empresa, mas que é impactado pelas suas atividades (JURAN, 1994). São os clientes associados aos negócios financeiros da empresa e que não participam diretamente da realização dos serviços e não trabalham na organização. Também, são conhecidos como clientes finais, que mantêm financeiramente a organização, adquirindo produtos e serviços (CINN, 2014). Cliente externo é todo aquele que, de alguma forma, é afetado pelo produto ou serviço disponibilizado. Portanto, quando se fala em atender aos anseios e necessidades dos clientes, está sendo assumindo uma postura num sentido mais amplo do que aquele normalmente considerado, da qualidade intrínseca do produto ou serviço. Em um sentido amplo, assumiram-se os efeitos sociais e ecológicos que o produto ou o serviço possa causar (NETO, 2012).

\subsection{Voz do cliente / voz da empresa}

Um passo importante no QFD é priorizar a voz do cliente, a fim de alocar recursos de forma adequada (MADDULAPALLI; YANG; XU, 2012). A voz do cliente representa os requisitos, necessidades e expectativas dos clientes. Os clientes declaram suas necessidades segundo seus pontos de vista e linguagem, utilizando termos dos bens que desejam obter. Entretanto, suas necessidades reais são pelos serviços que aqueles bens podem prestar. Como exemplo, um cliente deseja obter uma casa, porém o que ele realmente quer é um espaço para viver. E neste ponto, é que a não percepção das diferenças entre as necessidades declaradas e as reais podem resultar em sérias conseqüências (JURAN, 1994; MIGUEL, 2003).

A voz da empresa é a característica da qualidade que o produto ou serviço possui, ela corresponde aos atributos que a empresa confere ao produto ou serviço para que o mesmo atenda as qualidades exigidas, estando de acordo com as especificações do projeto (MIGUEL, 2003).

\subsection{Fluxo de informações}

Para uma empresa funcionar, é preciso uma quantidade significativa de informação. Processos e pessoas, tanto em organizações públicas quando em privadas, dependem da informação em seus processos decisórios. Para ser utilizada estrategicamente, é fundamental que a informação seja gerida em favor da sobrevivência e competitividade organizacional. A gestão da informação é responsável por gerir tanto os recursos internos quanto os externos à organização. Cada organização tem um fluxo de informação que lhe é peculiar e este fluxo é objeto importante da gestão que deve 
mapeá-lo, identificando pessoas, fontes de informação, tecnologia utilizada, produtos e serviços, compondo esse conjunto estruturado de atividades relativas à forma como a informação e o conhecimento é obtido, distribuído e utilizado (SILVA; TOMAÉL, 2007).

A análise do fluxo de informações nas organizações proporciona um melhor entendimento dos processos, possibilitando à empresa domínio de todas as informações dos mesmos. A informação é um importante ativo para o compartilhamento do conhecimento nas empresas. A gestão do fluxo de informações pode ser uma estratégia que maximiza recursos, em que as pessoas, por meio de suas atividades e produção, possam melhor compartilhar a informação. Portando, as informações devem ser claras, de fácil acesso e disponível para todos os envolvidos no fluxo de informação da empresa. Enfatizando que um dos fatores determinantes para o correto funcionamento de uma empresa é a forma como se trata a informação dentro dela (ZOCCHE, 2011; SILVA; TOMAÉL, 2007).

\section{Resultados}

\subsection{Pesquisa aberta e estruturada}

A pesquisa aberta (Q.Ab.), levou em consideração questão variadas e de âmbito generalizado, a fim de absorver dos entrevistados pontos chaves para o entendimento e caracterização das necessidades do estudo. Para a criação deste questionário, consideraram-se perguntas sobre o histórico do entrevistado, motivos e preferências, ambiente de trabalho, relação com as demais áreas do setor, relação com fornecedores e clientes, e as demandas da qualidade. Este questionário foi aplicado, em particular, com pessoas chaves de cada área.

Com as respostas, foram extraídas as exigências do cliente, que em alguns casos, o cliente é ao mesmo tempo fornecedor. Os pontos exigidos dos clientes e as características da qualidade (voz do fornecedor) foram divididos em duas tabelas, uma para cliente e outra para fornecedor, em três níveis: Requisitos de forma generalizada, apenas uma palavra; Requisitos descritos de forma clara e objetiva, mensuráveis; Frase real da requisição do cliente.

Com os resultados do Q.Ab., a partir dos requisitos dos clientes mensuráveis, foi possível criar o questionário estruturado, divido em 4 áreas: Relações de trabalho, com objetivo de mapear o ambiente; Funcionamento, com o objetivo de analisar as opiniões dos colaboradores; Observação, com objetivo de avaliar em escala Likert os itens mensuráveis do Q.Ab. (estes foram utilizados para compor as matrizes no QFD); Sugestão, com objetivo de saber se os colaboradores concordam ou não com as possibilidades de melhoria setor. Este questionário foi aplicado a uma população que representa $80 \%$ do total de colaboradores do setor.

\subsection{Mapa de relações}


Com a realização da pesquisa aberta, pode-se obter resposta às questões: Quem são os fornecedores internos? Quem são os clientes internos? A figura 1 representa uma sobreposição das relações, que baseada nas percepções e visão dos colaboradores de cada área, nos fornece um mapa completo do setor quanto ao seu fluxo de serviços e informações.

Figura 1 - Fluxo da relação entre as áreas

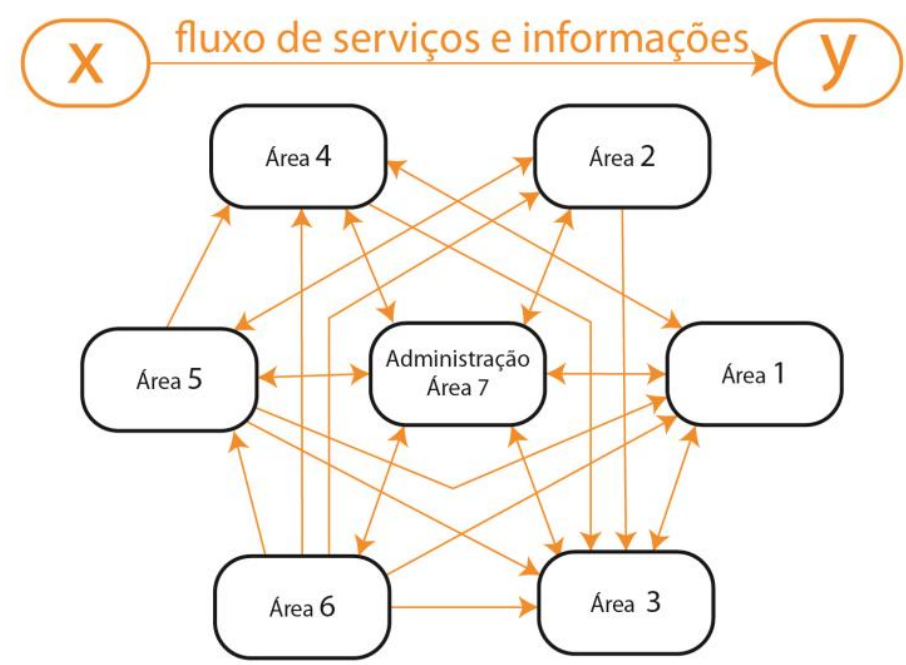

Fonte: Questionário aberto - Q.Ab, elaborado pelos autores (2015)

A partir da questão de atribuição de uma porcentagem, somando $100 \%$, presente no Questionário Estruturado (Q.Es.) na área de funcionamento, pôde-se definir uma consideração percentual sobre o que cada colaborador, das diferentes áreas, pensa sobre si. O gráfico da figura 2 representa as médias destas considerações sobre o quanto eles se consideram clientes internos e/ou fornecedores internos.

Figura 2 - Gráfico da relação de cliente interno e fornecedor interno por área

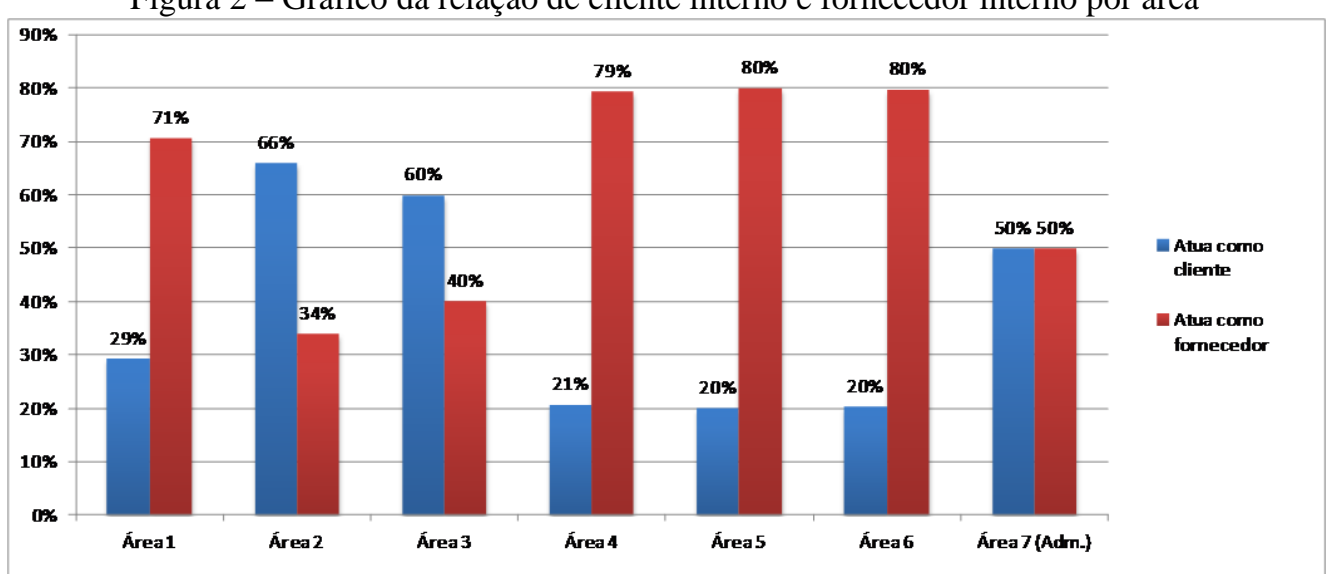

Fonte: Questionário estruturado - Q.Es, elaborado pelos autores (2015)

Com estes dados, pôde-se constatar que existem áreas onde seu papel principal é de fornecedor, enquanto outras seu papel principal é cliente. Assim, as áreas fornecedoras precisam atender aos requisitos das áreas clientes. A administração é a área onde atua exatamente no ponto de 
equilíbrio, onde esta relação é igual, uma vez que pela administração passa todas as informações, seja ela provinda tanto do ambiente interno quanto do ambiente externo.

\subsection{Aplicação do método QFD}

As matrizes do QFD variam conforme sua aplicação. Neste estudo, foram desdobradas as seguintes matrizes: (1) Matriz da Qualidade; (2) Matriz das Funções; (3) Matriz das Exigências; (4) Matriz dos Processos, cujo modelo conceitual utilizado é ilustrado na figura 3. A elaboração das mensurações das matrizes (qualidade planejada, argumento de vendas e a pontuação do interrelacionamento entre os itens da qualidade exigida e as características da qualidade) se deu através de reunião dos autores com supervisores e gerente.

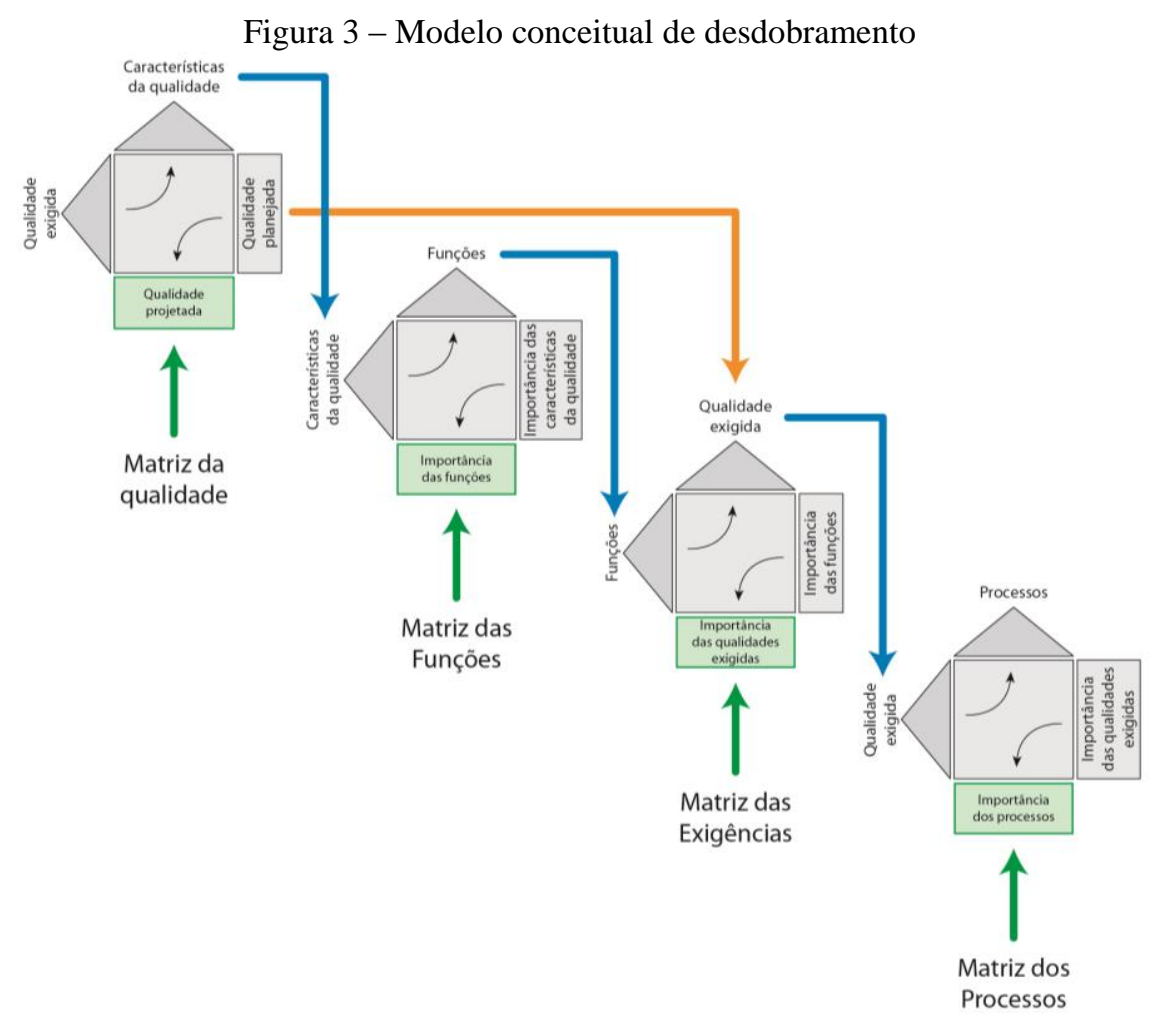

Fonte: Elaborado pelos autores (2015)

\subsubsection{Matriz da Qualidade (1)}

Para a construção da Matriz da Qualidade (figura 4) foram utilizados os itens mensuráveis extraídos da pesquisa aberta, que posteriormente, foram avaliados na pesquisa estruturada. Os itens das exigências dos clientes (qualidade exigida) foram posicionados a esquerda da matriz, e os itens características da qualidade foram posicionados no topo. Para o grau de importância, levou-se em consideração a média das respostas do questionário estruturado para cada item da qualidade exigida. A avaliação atual de cada item se deu através da nota estipulada pelo gerente do setor, gerando 
como resultados desta matriz uma qualidade planejada através do peso absoluto e relativo de cada item das características da qualidade.

Figura 4 - Matriz da Qualidade (1)

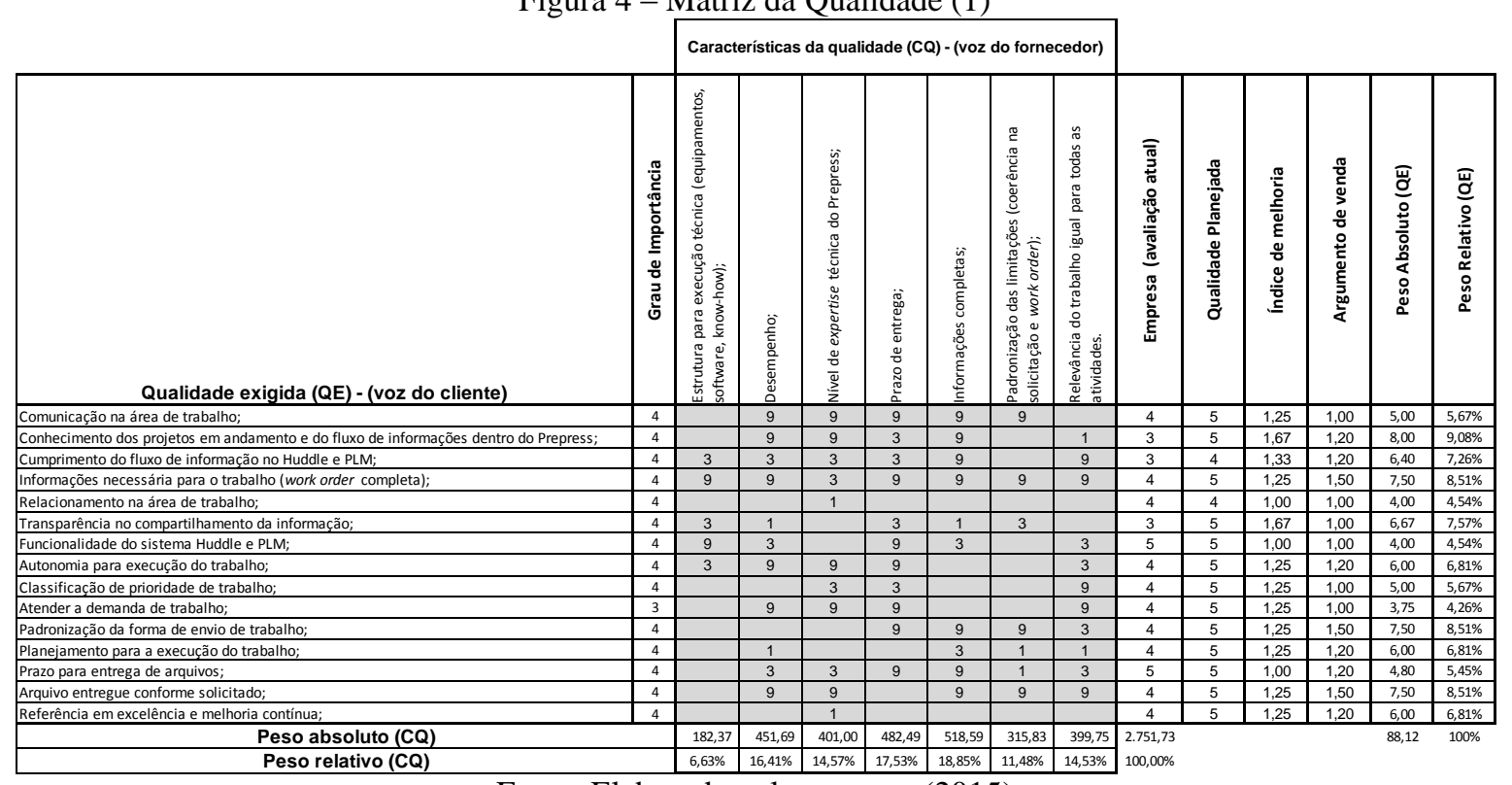

Fonte: Elaborado pelos autores (2015)

Através do peso absoluto e peso relativo identificou-se os itens mais importantes: Informações completas, Prazo de entrega e Desempenho, que juntos somam 53\% do peso dos itens.

\subsubsection{Matriz das Funções (2)}

Para a construção da Matriz das Funções (figura 5) foram utilizados os itens das características da qualidade, em ordem de importância, na esquerda da matriz, e as funções, por cargo hierárquico, no topo. Para o grau de importância, levaram-se em consideração os resultados encontrados na primeira matriz. Gerando como resultado desta matriz quais as funções (cargos) que possuem maior responsabilidade em garantir as características da qualidade como fornecedores.

Figura 5 - Matriz das Funções (2)

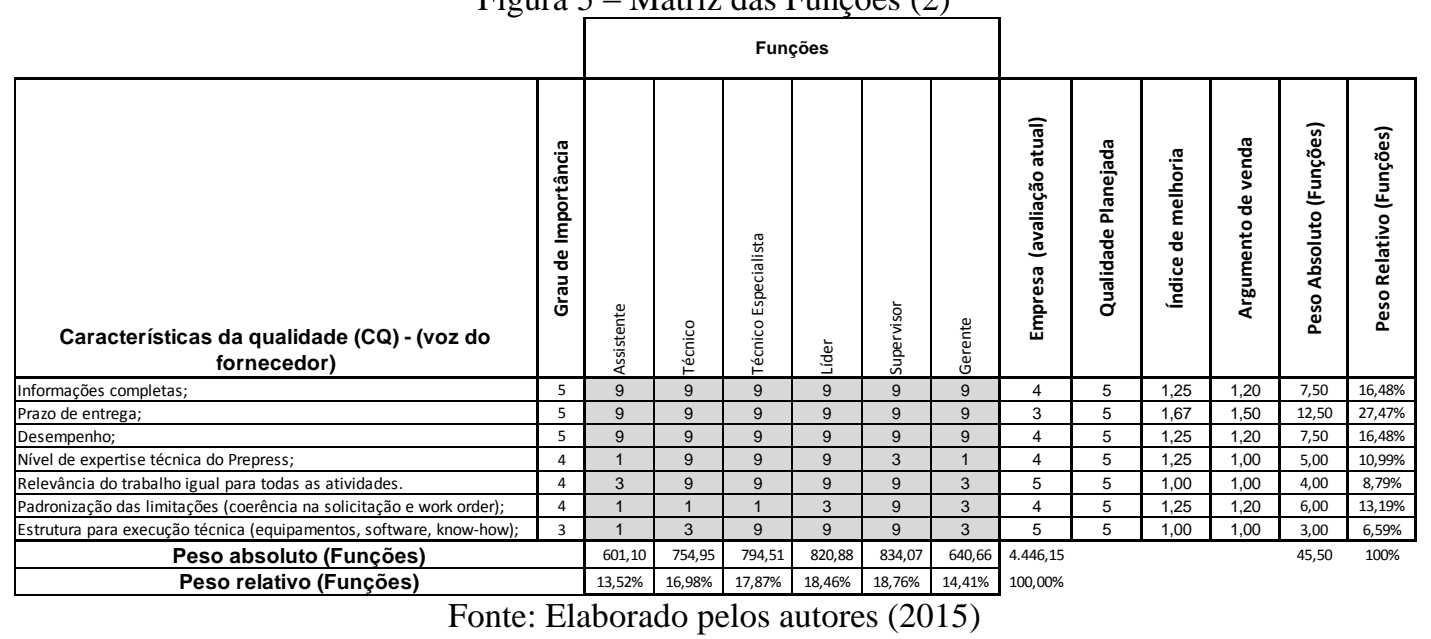


Através do peso absoluto e peso relativo identificou-se os cargos com maior responsabilidade: Supervisor, Líder e Técnico Especialista, que juntos somam 55\% do peso das funções.

\subsubsection{Matriz das Exigências (3)}

Para a construção da Matriz das Exigências (figura 6) foram utilizadas as funções, em ordem de responsabilidade, na esquerda da matriz, e as exigências dos clientes (qualidades exigidas), no topo. Para o grau de importância, foram atribuídos valores máximos para todos os cargos. Gerando como resultado desta matriz quais as qualidades exigidas pelos clientes que possuem maior importância em relação às funções.

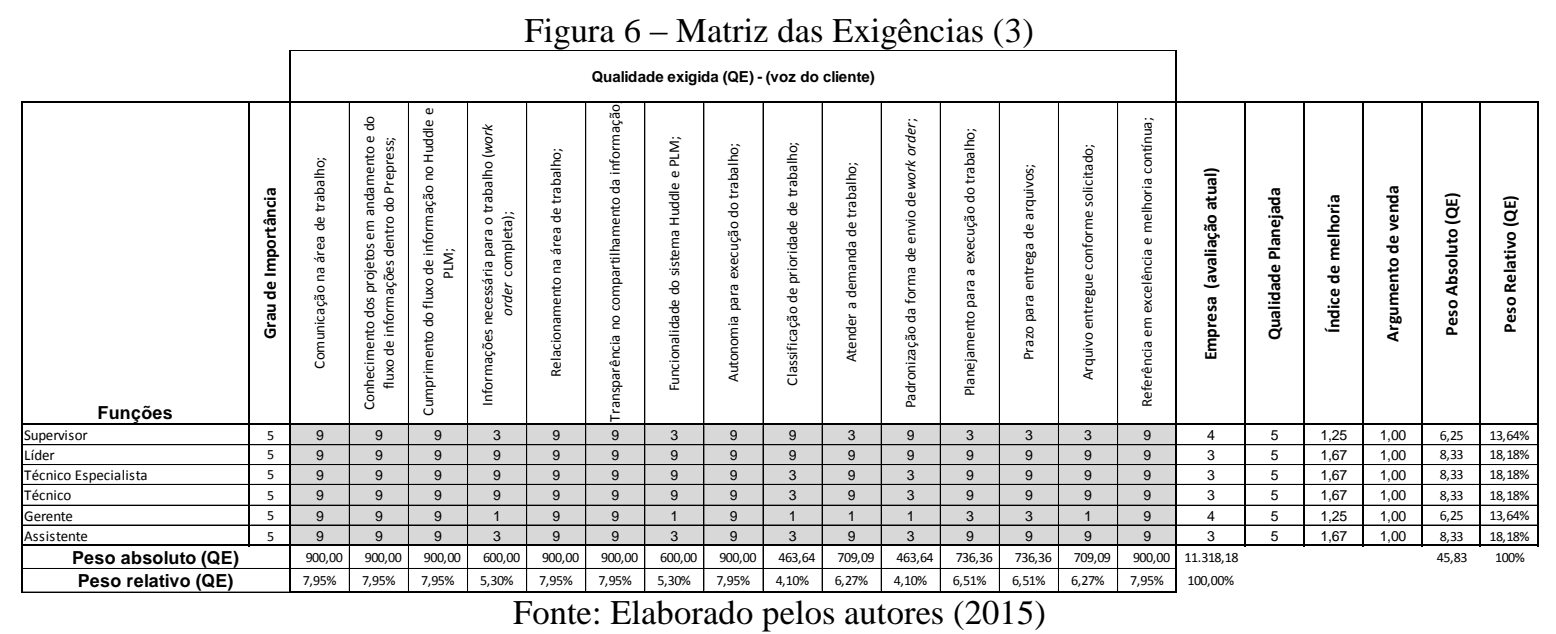

Através do peso absoluto e peso relativo identificou-se as qualidades exigidas mais importantes: Comunicação na área de trabalho, Relacionamento na área de trabalho, Transparência no compartilhamento da informação, Referência em excelência e melhoria contínua, Autonomia para execução do trabalho, Cumprimento do fluxo de informação no Huddle e PLM e Conhecimento dos projetos em andamento e do fluxo de informações dentro do Prepress, que apresentam o mesmo peso absoluto entre elas, e juntas somam $56 \%$ do peso das qualidades exigidas.

\subsubsection{Matriz dos Processos (4)}

Para a construção da Matriz dos Processos (figura 7) foram utilizadas as qualidades exigidas, em ordem de importância, na esquerda da matriz, e os processos, no topo. Os processos descritos nas colunas da matriz foram definidos a partir de um consenso na reunião do autor com os supervisores, no qual se fez uma relação dos processos em comum para as áreas, visto que nem todas as áreas contemplam todos os processos, mas deve-se mantê-lo na matriz, pois é aplicável a no mínimo uma área. Para o grau de importância, levou-se em consideração a média das respostas 
do questionário estruturado para cada item da qualidade exigida. A avaliação atual de cada item se deu através da nota estipulada pelo gerente. Geraram-se como resultados desta matriz quais os processos que possuem maior importância para garantir as qualidades exigidas pelos clientes.

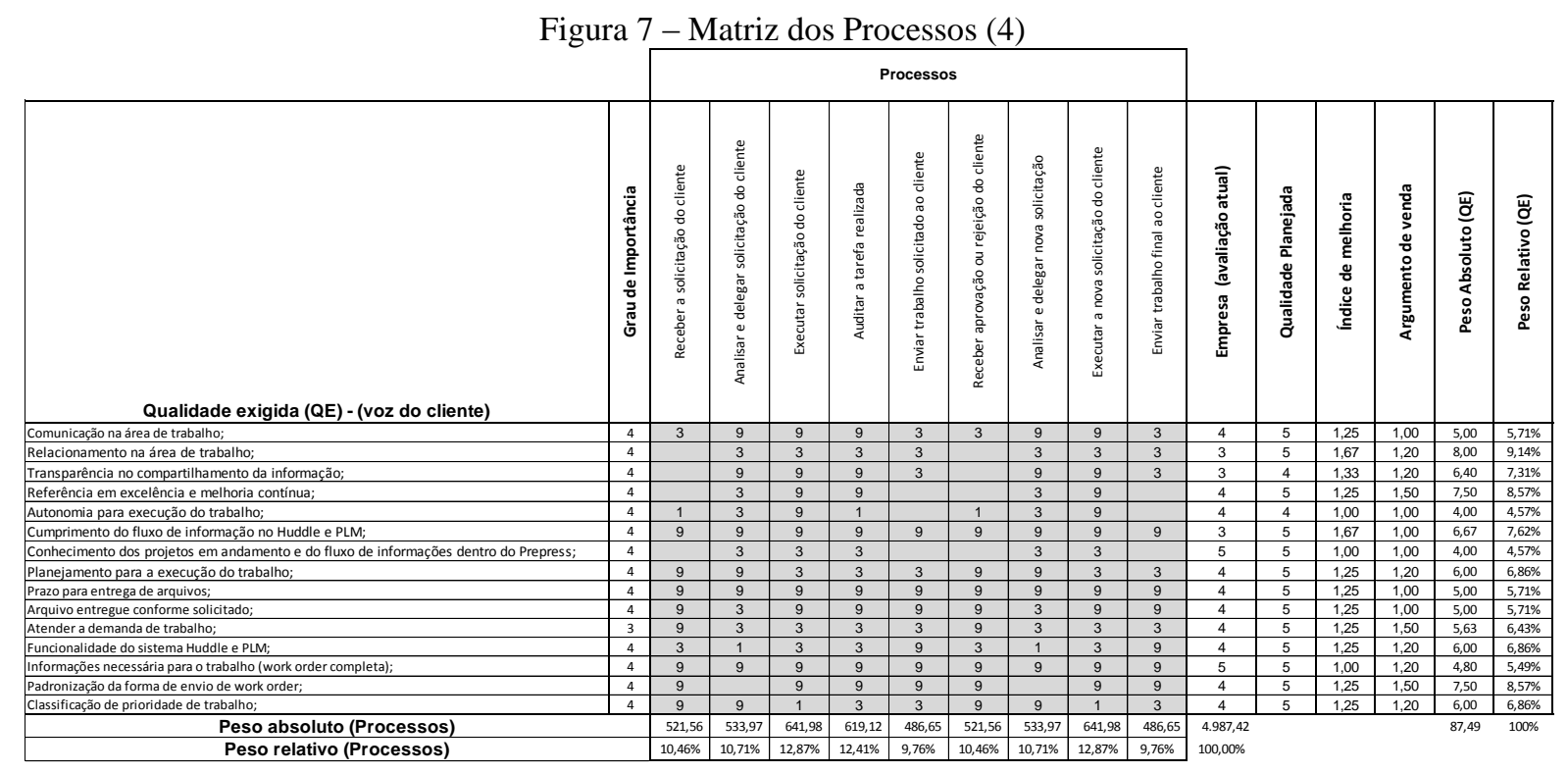

Fonte: Elaborado pelos autores (2015)

Através do peso absoluto e peso relativo identificou-se os processos com maior importância: Executar solicitação do cliente, Executar a nova solicitação do cliente, Auditar a tarefa realizada e Analisar e delegar a solicitação do cliente, que juntos somam $49 \%$ do peso dos processos.

\section{Discussão dos resultados}

Para garantir a qualidade, é preciso uma união de todos os itens, em especial os priorizados pelas matrizes. Os itens da Matriz da Qualidade (1) dizem respeito à forma como o fornecedor deve agir para garantir que seu produto ou serviço seja entregue com informações completas, com tudo que o cliente solicita de forma clara e objetiva, que seja entregue dentro do prazo estipulado e que o desempenho do fornecedor seja condizente com aquilo que lhe é solicitado.

$\mathrm{Na}$ Matriz das Funções (2), o cargo que em primeiro momento devem garantir que a qualidade será atendida começa pelo supervisor, que deve manter e garantir o funcionamento correto da sua área, atendendo aos requisitos dos seus clientes e seu gerente. O líder tem um papel muito importante para garantir a qualidade, pois é dele a responsabilidade da clarificação das ordens de trabalho e do entendimento correto da solicitação do cliente. O técnico especialista tem o papel funcional de garantir que seu trabalho atenda as exigências dos clientes e garanta a qualidade do trabalho.

Com a Matriz das Exigências (3), entendemos que a comunicação da área de trabalho deve ser priorizada para garantir a qualidade, juntamente com o relacionamento e a transparência no 
compartilhamento das informações, os demais itens estão relacionados a este mesmo tema, comunicação. No questionário estruturado, existe uma área sobre sugestões, que baseado em autores e nos próprios colaboradores questionados na pesquisa aberta, diversos itens foram analisados como viáveis para a melhoria contínua da qualidade, e algumas sugestões se encaixam para serem utilizadas como plano de ação: Melhor comunicação entre as áreas (71\%); Colaboração entre áreas e pessoas (63\%); Maior contato com colegas de outras áreas (45\%); Maior contato com gerente (39\%); e News, informativo semanal/mensal dos projetos em andamento (24\%).

A partir da Matriz dos Processos (4), os itens que se destacam como importantes para garantir a qualidade e as exigências dos clientes são as formas de executar a solicitação do cliente (a execução do trabalho propriamente dita), a auditoria da tarefa realizada (garantia interna que a execução está conforme o solicitado) e a correta análise e delegação da solicitação do cliente (aspecto fundamental no recebimento do trabalho que é papel dos líderes com aval dos supervisores).

\section{Considerações finais}

Este estudo buscou entender as necessidades dos clientes internos em relação ao fluxo de informações e relação entre as áreas do setor em estudo de uma empresa do ramo de bens de consumo. Em um primeiro momento, foi necessário entender o relacionamento entre as áreas e identificar as necessidades dos clientes internos através do processo de pesquisa. Após, aplicou-se o método QFD para priorizar os requisitos e então analisar os itens mais importantes.

A partir da prática do estudo constatou-se que a pesquisa aberta é um importante meio de obter um sincero ponto de vista dos acontecimentos do setor e descobrir os pontos chaves a serem analisados. Para o desdobramento das matrizes, percebeu-se uma dificuldade em relacionar os itens de forma numérica, sendo uma necessidade muito grande de ser realizado por uma equipe com conhecimentos sólidos sobre o funcionamento das áreas e então obter um melhor interrelacionamento dos itens.

Perceberam-se alguns pontos que devem ser melhorados para garantir a qualidade, sobretudo em relação à comunicação na área de trabalho. Também, percebeu-se uma falta de conhecimento de alguns colaboradores em relação ao fluxo de informações e ao relacionamento interno das áreas.

\footnotetext{
Abstract

The flow of information, ethics and organizational transparency are important to the success of companies. This paper presents a study about the relations of internal clients and internal supplier of prepress sector in a tobacco industry, with the use of quality tools to analyze the relationships. The aim is to analyze the internal working relationships of the productive areas of the sector and suggest improvements in the internal work process. The study was prepared seeking to meet the needs identified in each area. The methodology is based on bibliographic research and action research,
} 
focused on the mapping of the internal process and finding the points of greatest importance in relationships. Through the studies, customer requirements have been identified and key points to ensure the quality, which is evidenced a great need to improve internal communication between areas. The results indicate to perform an action to increase the level of knowledge of the projects and the degree of knowledge of the areas in relation to the functioning of the sector and the work being performed by colleagues from other areas.

Key-words: Quality function deployment; Information Flow; Internal Customer; Internal supplier.

\section{Referências}

BORGES, M. T.; DARWICH, A. R. S.; DE OLIVEIRA, C. M.; DA SILVA, D. F. A qualidade na relação clientefornecedor interno (back room versus front Office) determinando a satisfação do cliente externo. XLVI Congresso da Sociedade Brasileira de Economia, Administração e Sociologia Rural. Rio Branco - AC, 2008.

CARVAlHO, M. M.; PALADINI, E. P. Gestão da Qualidade - Teoria e Casos. Rio de Janeiro: Editora Elsevier - $5^{\mathrm{a}}$ Tiragem, 2006.

CHENG, L. C.; FILHO, L. D. R. M. QFD Desdobramento da função qualidade na gestão de desenvolvimento de produtos. São Paulo: Editora Edgard Blücher Ltda. - 2a Ed., 2010.

CHERMONT, G. S. A Qualidade na Gestão de Projetos de Sistemas de Informação. COPPE/UFRJ, M.Sc., Engenharia de Produção, 2001.

CHOWDHURY, M. H.; QUADDUS, M. A. A multi-phased QFD based optimization approach to sustainable service design. International Journal of Production Economics. v. 171, n. 02, P. 165-178, 2016. crossref

CINN. Cliente externo e Cliente interno. Centro de informação Metal Mecânica. Universidade Federal de Santa Catarina - SC. Disponível em: http://www.cimm.com.br/portal/verbetes/exibir/2733-cliente-interno-e-cliente-externo. Acesso em outubro de 2014.

FNQ. Cadernos de excelência: Clientes / Fundação Nacional da Qualidade. - São Paulo; Fundação Nacional da Qualidade. Série Cadernos de Excelência, n. 3, 2008.

HERRMANN, A.; HUBER, F.; ALGESHEIME, R.;TOMCZAK, T.An empirical study of quality function deployment on company performance. International Journal of Quality \& Reliability Management, v. 23, n. 04, p. 345-366, 2006. crossref

JURAN, J. M. A qualidade desde o projeto. Livraria Pioneira Editora - 2ª Ed., São Paulo - SP, 1994.

KAMVYSI, K.; GOTZAMANI, K.; ANDRONIKIDIS, A.; GEORGIOU, A. C.; Capturing and prioritizing students' requirements for course design by embedding Fuzzy-AHP and linear programming in QFD. European Journal of Operational Research. v. 237, n. 03, p. 1083-1094, 2014. crossref

KUBOTA, F. I. ; MIGUEL, P. A. C. Modularity and quality function deployment: a theoretical analysis of publications. Revista Gestão Industrial. v. 9, n. 03, p. 700-726, 2013.

MADDULAPALLI, A. K.; YANG, J. B.; XU, D. L. Estimation, modeling, and aggregation of missing survey data for prioritizing customer voices. European Journal of Operational Research. v. 220, n. 03, p. 762-776, 2012. crossref

MAICZUK, J.; JÚNIOR, P. P. A. Aplicação de ferramentas de melhoria de qualidade e produtividade nos processos produtivos: um estudo de caso. Qualit@s Revista Eletrônica ISSN 1677 4280, v. 14, n. 01, 2013.

MIGUEL, P. A. C. Desdobramento da Qualidade no Desenvolvimento de Filmes Flexíveis para Embalagens. Polímeros: Ciência e Tecnologia, v. 13, n. 02, p. 87-94, 2003.

MIGUEL, P.. A. C. Implementação do QFD para o desenvolvimento de novos produtos. São Paulo: Atlas S.A. 2008.

MIRANDA, R. L. Qualidade Total - rompendo as barreiras entre a teoria e a prática. São Paulo: McGraw-Hill - $2^{\text {a }}$ Ed., 1995. 
NETO, J. D. D. Qualidade no atendimento ao cliente externo. Fundação Pedro Leopoldo. Pedro Leopoldo - MG. 2012.

OLIVEIRA, J. A.; DE NADAE, J.; OLIVEIRA, O. J.; SALGADO, M. H. A study on the use of quality systems, programs and tools in companies of interior of São Paulo State. Production, v. 21, n. 04, p. 708-723, 2011. crossref

PALADINI, E. P. Gestão da Qualidade no processo. São Paulo: Editora Atlas, 2006.

PEROTTI, A. P.; SCHMIDT, A. S.; GODOY, L. P. QFD in the planning of the quality of helmet foroccupants of motorcycles. Revista Gestão Industrial. v. 05, n. 02, p. 134-158, 2009.

SANTANA, V. Manual Preliminar: QFD - Quality Function Deployment - Aplicações. Universidade Federal do Paraná - Curitiba - PR. 2004.

SILVA, T. E.; TOMAÉL, M. I. A gestão da informação nas organizações. Universidade Estadual de Londrina. Inf. Inf., Londrina - PR, v.12, n. 02, 2007.

STEFANO, N.; FERREIRA, A. R.; JOÃO, D. M.; GODOY, L. P. Satisfação dos clientes interno e externo mensurada através da escala servqual e do modelo gap em uma empresa prestadora de serviços. IV Congresso Nacional de Excelência em gestão. Niterói - RJ, 2008.

ZOCCHE, L. Fluxo de informações em uma indústria moveleira: um estudo de caso. Monografia (Bacharel em Engenharia de Produção) - Universidade Tecnológica Federal do Paraná, 2011.

\section{Dados dos autores:}

Nome completo: Leonardo Moraes Aguiar Lima dos Santos

Filiação institucional: Universidade de Santa Cruz do Sul

Departamento: Engenharia, Arquitetura e Ciências Agrárias

Função ou cargo ocupado: Graduado em Engenharia de Produção

Endereço completo para correspondência: Universidade de Santa Cruz do Sul, Av. Independência, 2293

Bairro Universitário - CEP: 96815-900 - Santa Cruz do Sul - RS / Brasil.

Telefone para contato: (51) 3717-7300

E-mail:leomals@hotmail.com

Nome completo: Daniel Augusto Hoppe

Filiação institucional: Universidade de Santa Cruz do Sul

Departamento: Engenharia, Arquitetura e Ciências Agrárias

Função ou cargo ocupado: Professor

Endereço completo para correspondência: Universidade de Santa Cruz do Sul, Av. Independência, 2293

Bairro Universitário - CEP: 96815-900 - Santa Cruz do Sul - RS / Brasil.

Telefone para contato: (51) 3717-7300

E-mail:danielhoppe@unisc.br 
Nome completo: André Luiz Emmel Silva

Filiação institucional: Universidade de Santa Cruz do Sul

Departamento: Engenharia, Arquitetura e Ciências Agrárias

Função ou cargo ocupado: Professor

Endereço completo para correspondência: Universidade de Santa Cruz do Sul, Av. Independência, 2293

Bairro Universitário - CEP: 96815-900 - Santa Cruz do Sul - RS / Brasil.

Telefone para contato: (51) 3717-7300

E-mail:andresilva@unisc.br

Nome completo: Patrícia Paz Silva

Filiação institucional: Universidade de Santa Cruz do Sul

Departamento: Administração

Função ou cargo ocupado: Bacharel em Administração

Endereço completo para correspondência: Universidade de Santa Cruz do Sul, Av. Independência, 2293

Bairro Universitário - CEP: 96815-900 - Santa Cruz do Sul - RS / Brasil.

Telefone para contato: (51) 3717-7300

E-mail: patriciapaz2306@gmail.com

Nome completo: Lucas Vinícius Reis

Filiação institucional: Universidade de Santa Cruz do Sul

Departamento: Programa de Pós-Graduação em Sistemas e Processos Industriais

Função ou cargo ocupado: Mestrando em Sistemas e Processos Industriais

Endereço completo para correspondência: Universidade de Santa Cruz do Sul, Av. Independência, 2293

Bairro Universitário - CEP: 96815-900 - Santa Cruz do Sul - RS / Brasil.

Telefone para contato: (51) 3717-7300

E-mail: lucasviniciusreis@gmail.com

Submetido em: 23-05-2016

Aceito em: 21-09-2016 